\title{
Analysis of Triage Application in Emergency Department
}

\author{
Ali Kemal Erenler*, İnanç Özel, Yasemin Ece, Mine Karabulut, Aysun Oruçoğlu, Eşref Çiftçi \\ Hitit University Çorum Education and Research Hospital, Department of Emergency Medicine, Çorum, Turkey \\ Email: " akerenler@hotmail.com
}

Received 6 July 2015; accepted 17 August 2015; published 21 August 2015

Copyright (C) 2015 by authors and Scientific Research Publishing Inc.

This work is licensed under the Creative Commons Attribution International License (CC BY).

http://creativecommons.org/licenses/by/4.0/

(c) (i) Open Access

\begin{abstract}
Objectives: In this study, we aimed to determine the current status of Green Zone (GZ) application in our Emergency Department (ED). We also sought workload and economic burden of GZ on both healthcare providers and health system. Methods: We analyzed the medical data of patients admitted to the GZ of our ED in a three-year period. Demographical characteristics, complaints on admission, number of revisits and economical cost of the patients were determined. Results: During 3-year period a total of $\sim 900,000$ patients were admitted to Hitit University Corum Education and Research Hospital ED. Of these patients, 87,089 patients were treated in GZ. Upper respiratory system disease was the leading complaint on admission. Mean length of stay in ED for these patients was found to be $\mathbf{2 2 . 2}$ minutes. When repeated visits were investigated, it was found that 3029 patients presented twice to the GZ. Conclusion: Certain measures to reduce number of nonemergent patients presenting to ED must be taken immediately. Or else, dissatisfaction of both healthcare providers and patients shall remain as a potential cause of unwanted events in overcrowded EDs in the future.
\end{abstract}

\section{Keywords}

Triage, Overcrowding, Green Zone, Emergency Department

\section{Introduction}

Emergency medicine (EM) is a specialty for 20 years in Turkey. By 2003, it is estimated that about 1000 specialists work in State, Education and Research, University and private hospitals. Unfortunately, speciality in EM could not reach to desired level of popularity in Turkey. Reasons for low popularity of this speciality may be related to many reasons such as higher exposure rates to violence in the Emergency department (ED), poor

${ }^{*}$ Corresponding author.

How to cite this paper: Erenler, A.K., Özel, I., Ece, Y., Karabulut, M., Oruçoğlu, A. and Çiftçi, E. (2015) Analysis of Triage Application in Emergency Department. Open Journal of Emergency Medicine, 3, 13-17.

http://dx.doi.org/10.4236/ojem.2015.33003 
working conditions, overcrowding, lack of sufficient employee rights, inadequate education of residents, simplicity in prosecuting against doctors, etc. [1].

Overcrowding is one of the most important problems in the ED which causes decrease in EM popularity. It causes not only motivation disorders of employee but also degradation of the quality of care, increased costs and patients' dissatisfaction [2] [3].

Triage is a continous process for classification of the patients according to priority [4]. It's reported that employment of triage scales in EDs has led to significant reduction in waiting times and improved patients' satisfaction [5].

In Turkey, EDs have been divided into three sections as green, yellow and red zones to have patients obtain appropriate healthcare according to their priority.

Green zone (GZ) is established to care outpatients with the least emergent situation. However, in Turkey, as having the most overcrowded EDs in Europe, GZ has begun to be misused by people.

Besides factors contributing to increased patient volume within the emergency department such as limited physical space and availability of bed space in the intensive care unit, increasing proportions of geriatric individuals in the general population, personnel shortages, delayed consultation with specialists, and delays in imaging and laboratory services, non-urgent patients' use of EDs, rather than primary care settings makes EDs more problematic and chaotic [2] [6].

The most important cause of bottleneck in the ED seems to be a growing population with non-urgent complaints. Non-urgent patients' use of EDs, rather than primary care settings, allows them to be treated without an appointment in a setting with modern and high-quality technologies [2].

People who do not want to wait in lines in polyclinics prefer to use EDs and ED physicians are forced to give healthcare to everyone entering ED whether urgent or not. Otherwise, doctors have to deal with patients' complaints transformed into investigations and lawsuits against them.

Patients complain for various reasons if they become dissatisfied with the service. These complaints may result from unmet expectations or may reflect poor service quality [7].

Most healthcare facility structured new areas and rooms for green zone to give better service to these people. Doctors trained to help emergency patients are being assigned to these places and expected to serve GZ patients. However, efforts to canalize these people to primary care settings are inadequate and reluctant.

In this study, we aimed to determine the magnitude of this burden on emergency care system and underline importance and necessity of dedicating EDs to emergent patients.

\section{Materials and Methods}

This study was conducted in ED of Hitit University Çorum Education and Research Hospital. Patients presented to ED GZ in a 3-year period (between January 2012 and December 2014) were investigated retrospectively. From the computer database of the Hospital, demographical characteristics, initial complaints, length of stay (LOS), number of revisits and economic burden of GZ were investigated. Data were analyzed using Microsoft Excel XP and SPSS (version 13.0, SPSS Inc., Chicago, Illinois, USA). Descriptive analyses were given as numbers and percentages.

\section{Results}

During 3-year period a total of $~ 900,000$ patients were admitted to Hitit University Çorum Education and Research Hospital ED. Of these patients 87,089 patients were managed in GZ. Among these patients 41,870 were male (48.08\%) and 45,219 (51.92\%) were female. Mean age was found to be 27 years old. Mean LOS in ED was 22.2 minutes. When patients were investigated according to complaints on admission, it was determined that upper respiratory system disease was the leading complaint $(n=42,841)$. It was followed by gastrointestinal system disorders (5152), myalgia $(n=4471)$, headache $(n=3315)$, and lumbalgia $(n=2472)$. Distribution of patients according to their initial diagnoses are summarized in Table 1.

In 2014, 26,514 patients were admitted to our GZ. When repeated visits were investigated, it was found that 3029 patients presented twice, 629 patients: 3 times, and 176 patients: 4 times. It was also recorded that 1 patient visited green zone 21 times in 1-year period. Number of patients' revisits are summarized in Table 2.

We also calculated the economic burden of GZ on ED and healthcare system. In 2014, mean money spent per 
Table 1. Initial diagnoses of the patients admitted to the green zone in the emergency department.

\begin{tabular}{ccc}
\hline Diagnoses & Number & Percentage \\
\hline Upper Respiratory Tract Infection & 42,841 & 49.1 \\
Gastrointestinal Disorders & 5152 & 5.9 \\
Myalgia & 4471 & 5.1 \\
Headache & 3315 & 3.8 \\
Lumbalgia & 2472 & 2.8 \\
Hypertension & 1504 & 1.7 \\
Urinary Tract Infection & 1268 & 1.4 \\
Dismenorea & 799 & 0.9 \\
\hline
\end{tabular}

Table 2. Number of revisits to the green zone.

\begin{tabular}{ccc}
\hline Number of Revisits & Number of patients \\
\hline 2 & 3029 \\
3 & 629 \\
4 & 176 \\
5 & 49 \\
6 & 24 \\
7 & 7 \\
\hline
\end{tabular}

patient was found to be 25.2 Turkish liras. A total of 800,846 Turkish liras was spent for non-emergent patients admitted to the GZ. This amount involves only examination, imaging and laboratory costs.

\section{Discussion}

Çorum is a relatively small city located in middle of Karadeniz Region with its population of 243,698 living in the city center according to 2014 census data. In the city center, there is one Education and Research Hospital affiliated to Hitit University. In the ED of this hospital, 6 specialists in EM and 11 practitioners (4 in pediatric ED) are employed. It serves as the only trauma, toxicology and emergency center of the city. As a city with a population of 243,698, having an annual ED visit number of $~ 300,000$, makes it an overcrowded and problematic place for both ED staff and patients. Like EDs in other parts of Turkey, the number of annual ED visits exceed the number of population of the city.

On every shift, 2 practitoners and an EM specialist gives service in the ED. During the daytime, a $4^{\text {th }}$ physician additionally serves in the GZ.

There are reports in the literature that female patients visit EDs more frequently than males [8]-[10]. Our study also suggests that the ratio of female patients is slightly higher than male patients. However, in some parts, different ratios were reported. In a study by Köse et al., the number of male patients was found to be bigger than females [4]. In a 1-year analysis with 115,185 patients by Türkdoğan et al., it was reported that a total of 47,641 patients were categorized as green. Only 3537 patients were brought by ambulance. Lower proportion of GZ patients in our study may be due to involvement of pediatric patients in our study. There are also reports in the literature revealing that proportion of non-emergent patients may reach up to 59.1\% [10] [11].

In our study, mean age of the patients admitted to GZ was found to be 27. It is obvious that patients in this age range is the least risky group for metabolic, cardiac and neurological disorders. This finding is correlated with the hypothesis that most of these patients may be treated by family physicians and physicians in polyclinics.

In our study, we determined that upper respiratory system disorders were the most common reason for admission to GZ. It was followed by myalgia and headache. Similarly, in a study evaluating the reasons of applying, the most common complaints were detected just as sore throat $(n=25,682,20.0 \%)$, myalgia $(n=7285$, $5.7 \%)$, stomach ache $(n=5125,4.0 \%)$, breath ache $(n=3914,3.1 \%)$, out of breath ache $(n=3552,2.8 \%)(11)$. Moreover, in a study by Zeytin et al., respiratory system disorders were found to be the leading cause for presentation in the ED [10]. 
Green zone patients cause overcrowding and bottle-neck formation in the ED. As the ED gets overcrowded, time left for anamnesis and physical examination decreases. Or else, LOS in the ED prolongs. This results in occuptaional dissatisfaction of physicians and aggression of patients and nearbys.

In a study, it was reported that the major factors affecting patient satisfaction levels were the attitudes and medical care experience levels of doctors and nurses in charge at the emergency service and the level of information provided to patients throughout treatment and waiting periods [12]. All these complaints occur as a result of overcrowding in the ED.

In a study, it was reported that the patients' average LOS in the emergency department was 183.6 minutes ( three hours) [10]. In another study, avarage LOS in the ED was reported to be 164.1 minutes [2]. For the 900 patients included in the study by Mahmoodian et al. revealed that the median waiting time from arrival to first visit by physician was 8 (5 - 14) minutes [13]. However, in the present study, when GZ was investigated solely, we determined that this period was relatively short (22.2 minutes). This may also be a factor for patients to prefer GZ in the ED instead of family physicians.

To our knowledge, economic evaluation of GZ was not done before. Even though the authors of this article consider that healthcaring cannot be compared by economical parameters, it is determined that an amount of 800,846 Turkish liras are spent for these patients. This number does not involve money paid for drugs bought from pharmacies. By decreasing the number of patients presented to GZ, this money may be canalized to eliminate deficiencies in EDs.

Our study also has some limitations. Because of the difficulties in computer system, the number of patients in our study does not involve those who present to the GZ of ED for previously prescribed injections and dressings. The exact number of patients contributing to the overcrowding of ED is much bigger than that mentioned in our study.

\section{Conclusion}

Green zone is established to reduce overcrowding in the ED. Lack of number of adequate staff in the EDs leads to challenges in assignment of physicians, nurses and secretaries to these places. Inadequate measures taken to keep non-emergent patients away from EDs also contribute to overcrowding, and thus dissatisfaction and violent acts. Managers must focus on not "how to serve these patients in the ED" but "how to canalize them to primary health care facilities". In an ED with constant number of physicians, assigning a physician to GZ leads to nothing but reduction in the number of physicians who are supposed to take care of "real" emergent patients. This study shows that a standart GZ patient is young male/female with upper respiratory disorders (cold, flu, pharengytis, tonsillitis, etc.). These patients may easily be treated by family physicians or specialists in polyclinics.

\section{References}

[1] Satar, S., Cander, B., Avcı, A., Açıkalın, A., Orak, M., Açin, M., et al. (2013) Why Speciality in Emergency Medicine Is Not Preferred? Journal of Academic Emergency Medicine, 12, 234-236. http://dx.doi.org/10.5152/jaem.2013.21548

[2] Erenler, A.K., Akbulut, S., Güzel, M., Cetınkaya, H., Karaca, A., Turkoz, B., et al. (2014) Reasons of Overcrowding in the Emergency Department: Experiences and Suggestions of an Education And Research Hospital. Turkish Journal of Emergency Medicine, 14, 59-63. http://dx.doi.org/10.5505/1304.7361.2014.48802

[3] Akpınar, A.T. and Taş, Y. (2011) A Research to Determine the Relationship between Level of Burnout and Job Satisfaction in Emergency Department Personnel. Turkish Journal of Emergency Medicine, 11, 161-165. http://dx.doi.org/10.5505/1304.7361.2011.89804

[4] Köse, A., Köse, B., Öncü, M.R. and Tuğrul, F. (2011) Admission Appropriateness and Profile of the Patients Attended to a State Hospital Emergency Department. Gaziantep Medical Journal, 17, 57-62. http://dx.doi.org/10.5455/GMJ-30-2011-27

[5] Taylor, C. and Benger, J.R. (2004) Patient Satisfaction in Emergency Medicine. Emergency Medicine Journal, 21, 528-532. http://dx.doi.org/10.1136/emj.2002.003723

[6] Mahsanlar, Y., Parlak, İ., Yolcu, S., Akay, S., Demırtas, Y. and Eryıgıt, V. (2014) Factors Affecting the Length of Stay of Patients in Emergency Department Observation Units at Teaching and Research Hospitals in Turkey. Turkish Journal of Emergency Medicine, 14, 3-8. http://dx.doi.org/10.5505/1304.7361.2014.58224

[7] Zengin, S., Al, B., Yavuz, E., Şen, C., Cindoruk, S. and Yıldırım, C. (2012) Patient and Relative Complaints in a 
Hospital Emergency Department: A 4-Year Analysis. Turkish Journal of Emergency Medicine, 12, 163-168. http://dx.doi.org/10.5505/1304.7361.2012.55823

[8] Oktay, C., Cete, Y., Eray, O., Pekdemir, M. and Gunerli, A. (2003) Appropriateness of Emergency Department Visits in a Turkish University Hospital. Croatian Medical Journal, 44, 585-591.

[9] Kılıçaslan, İ., Bozan, H., Oktay, C., et al. (2005) Demographic Properties of Patients Presenting to the Emergency Department in Turkey. Turkish Journal of Emergency Medicine, 5, 5-13.

[10] Zeytin, A.T., Cevik, A.A., Acar, N., Kaya, S. and Ozcelık, H. (2014) Characteristics of Patients Presenting to the Academic Emergency Department in Central Anatolia. Turkish Journal of Emergency Medicine, 14, 75-81. http://dx.doi.org/10.5505/1304.7361.2014.91489

[11] Türkdoğan, K.A., Kapçı, M., Akpınar, O., Duman, A., Bacakoğlu, G., Türkdoğan, F.T., et al. (2013) Demographic Characteristics of Patients a State Hospital Emergency Service: Meta-Analysis of 2011. Journal of Clinical and Experimental Investigations, 4, 274-278. http://dx.doi.org/10.5799/ahinjs.01.2013.03.0283

[12] Gültekin Akkaya, E., Bulut, M. and Akkaya, C. (2012) The Factors Affecting the Level of Patients' Satisfaction of the Applicants for Emergency Service. Turkish Journal of Emergency Medicine, 12, 62-68. http://dx.doi.org/10.5505/1304.7361.2012.67689

[13] Mahmoodian, F., Eqtesadi, R. and Ghareghani, A. (2014) Waiting Times in Emergency Department After Using the Emergency Severity Index Triage Tool. Archives of Trauma Research, 7, Article ID: e19507. 